\title{
The hard Problem
}

\section{A study in the modern and contemporary theories interpretation of consciousness}

\author{
Assistant Prof. Baqer Ibrahim ALzaidy \\ Philosophy department, College of Arts, Wasit University \\ Iraq \\ E-Mail: balzubaidy@uowasit.edu.iq
}

\begin{abstract}
Consciousness, This concept is widely circulated in many fields of knowledge, and is automatically realized in ourselves once we have a simple reflection on what is going on within our minds. However, it is one of the most problematic concepts, and the most difficult to explain. Previously consciousness was accepted intuitively, as an directly given to man, man is a rational being without the rest of living beings, but why he is rational? A question no one answer, either old or present, a completely and scientifically accepted. This research" Hard problem- A study in the modern and contemporary theories interpretation of consciousness" does not claim to provide this answer, but rather scans the various answers provided to explain this difficult problem. Analyzing them and revealing their weaknesses and strengths.
\end{abstract}

Keywords: Hard problem, consciousness, mind, dualism, monism, Chalmers, john searl, brain

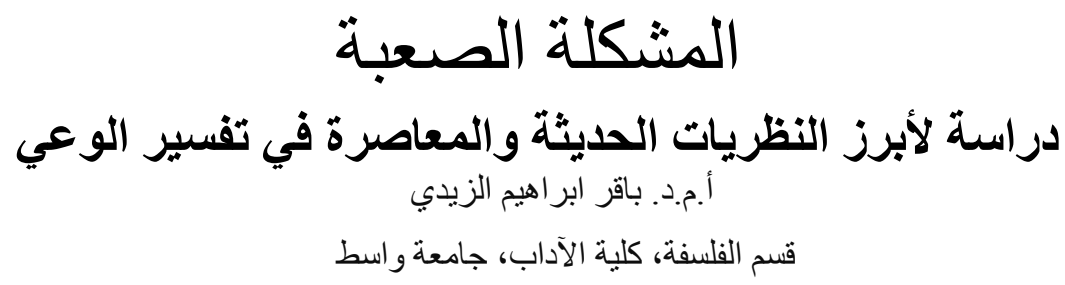

خلاصة البحث

الوعي مفهوم متداول بشكل واسع في الفلسفة وحقول معرفية أخرى كثيرة ،وهو مدرك في كل واحد منا بشكل تلقائي ،بمجرد أن نقوم بتأمل بسيط لما يجري داخل عقولنا، وفي ذو اتتا. ومع ذللك ، يعد هذا المفهوم من أكثر المفاهيم اشكالية ،واكثرها استعصاء على التفسير .سابقا كان يتم قبول الوعي بشكل بديهي، باعتباره معطى تلقائي للإنسان ،فالإنسان كائن عاقل دون بقية الكائنات الحية ،اما لماذا هو عاقل ؟ولماذا هو يمنلك وعيا دون بقية الكائنات ؟ فهذا مالم يجب عليه أحد لا قديما ولا حاليا ،بصورة شافية ومقبولة علميا ـ و لا يدعي هذا البحث انه يقدم هذه الإجابة ،بل انه يقوم بمسح مختلف الإجابات التي قدمت لتفسير هذه المشكلة الصعبة. محلا إياها وكاشفا عن نقاط ضعفها وقوتها. الكلمات المفتاحية:المشكلة الصعبة، الوعي،العقل، الثنائية، الواحدية، جالمرز، جون سيرل، الدماغ 
the Journal of of Consciousness -) ونالك مجلة دراسات الوعي (Studies مجموعة مناقثات عامة حول الوعي على شبكة الإنترنت. وفي جامعة أريزونا في الولايات المتحدة مركزًا للبحوث متخصص في دراسات الوعي، وتنظم الجامعة ايضا سلسلة من المؤتمرات النصف سنوية الهامة Encyclopedia of philosophy.com" عنذ عام 1994. "Stanford,

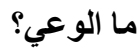
لكن ما المقصود بالو عي تحديدا؟ لنبدأ من قو اميس الفلسفة ومن التعريفات التي تعطيها لهذا المفهوم. الوعي يتحدى التعريف ، لكنه موجود ومدرك بشكل تلقائي، و ثمة معايير تبين لنا متى يمكن لكائن العضوي ان يوصف بانه يمنلك وعيا، مثل العواطف، الأحلام، التفكير المنطقي بالقضايا ،الادراك الذاتي. وثمة جدل حاد حول ماهية الوعي، ما اذا كان بالمسنطاع در استه، وكيفية در استه حال امكانها؟ ما الدور السببي الذي يقوم به؟ إن كان له دور سببي- بصرف النظر عن واقعة كونه تحقق دائما حتى الآن في أنساق بيولوجية معينةـ لم يتوجب أن يتحقق على هذا النحو؟ "هوند تدرش.ج3.دون تاريخ، ص1041". تعريف يبرز الصعوبات ويثير أسئلة مركزية، لكن دون اجابات مقترحة . ويجب ان نميز بين معنيين للوعي، المعنى القوي و المعنى الضعيف ، فالمعنى الأول يتضمن انعكاس الوعي وأيضا يتضمن الادرالك الذاتي كمقابل للأشياء الاخرى، بمعنى إدر الك المرء لذاته و أحو اله و أفعاله إدر اكا مباثرا كبهذا المعنى فان الوعي يتضمن مقدرة الذكاء والتعقل والتي تكون مقصورة على البشر لكن بالمعنى الضعيف يتضمن كل تجربة حسية ،بالأخص الثعور بالألم ومن ثم تنشأ مشكلة ماهي طبيعة العلاقة بين هذين المعنيين " Lacey.1996,p.65. (ابراهيم مدكور (2150ص،1983.

يمثل الوعي احد المعطيات الأساسية للفكر الذي لا يمكن تفكيكيه الى عناصر أبسط . لا يمكن حد الوعي ،انما يمكننا ان نعرف حق المعرفة ما هو الوعي ،ولكننا لا نستطيع ابلاغ الاخرين وبلا التباس، تعريفا لما ندركه نحن ادراكا واضحا. الوعي هو أصل كل معرفة هو ما نكون عليه، ادنى فأدنى، عندما نقع وقوعا في نوم بلا احلام، وما نكون عليه اكثر فاكثر عندما توقظنا الضجة رويدا رويدا. "(لالاند.

(211) 2001
تعد دراسات الوعي والتعمق فيه حقل دراسي جديد وسريع التطور، تتداخل فيه تخصصات متعددة تتضمن علم النفس، و الفلسفة، و الفيزياء ،وعلم الاجتماع ،و الدين، والأنظمة الديناميكية والرياضيات وعلوم الكمبيوتر و علم الأعصاب و الفن والبيولوجيا وعلم الإنسان و علم اللغة. في أوائل التسعينيات من القرن الماضي، عده كثير من الدارسين أهم مشكلة لم يتم حلها إلى الآن في العلوم. فضلا عن ذلك ،فإن الوعي هو قضية رئيسة في الحوار المستمر بين العلم والدين. النظرة السائدة لتفسير الوعي في العلوم اليوم، هي نظرة مادية اختز الية في معظمها ، وقد حقق هذا التفسير نجاحات مهمة، لكنه يو اجه أيضًا صعوبات و اعتر اضات لا تقل أهمية ولم يتم الإجابة عليها بصورة مرضية . فالإنسان لا يمكن ان يكون مجرد تجمع لمجموعة من الخلايا العصبية وفق نمط معين، إن معظم الناس، بما فيهم من المتعدقين في دراسات الوعي، وفي علم الأعصاب بالذات ، يعتقدون أن حياة الإنسان وتمظهره الواعي هو أكبر بكثثر مما يمكن رؤيته على مستوى الخلايا العصبية البحتة. لذا كان الوعي وماز ال يعد مشكلة يكاد يتعذر حلها . في الوقت الحاضر أصبح بطلق على مشكلة الوعي اسم (المشكلة الصعبة (Hard problem جالمرز" عام 1994وذللك للتمبيز بين هذه المشكلة الخطيرة برأيه، وما يدعوه بالمشكلات السهلة، وهي تلك المشكلات التي نعرف كيف نحلها من حيث المبدأ حتى ان لم نكن حلانها بعد وتتضمن هذه المشكلات الادر الك الحسي و التعلم او الانتباه او فعاليات الذاكرة وكيفية تمييز الاشياء او الاستجابة للمؤثرات وكيف يختلف النوم عن اليقضة كل هذه الامور مشكلات سهلة على حد قوله اذا ما قورنت بالمشكلة الصعبة ـ "بلاكمور. 2016،ص10" و الحقيقية ان استخدام هذا المصطلح ليست جديدة نماما كربما الجديد هو الصياغة له ، فقد وجدت اثناء البحث ان (هنتر مبد) قد استخدمه في كتابه (الفلسفة انواعها ومشكلاتها) وذللك خلال عرضه للمشكلة."هنتر ميد،1975، صنه 168). اما في مطلع القرن الحادي والعشرين ،فقد اصبحت دراسات الوعي تشكل مجتمعًا محترفًا من المتخصصين ينتظمون في جمعية هي: "جمعية the Association for the Scientific " الدر اسات العلمية للوعي"ASSC "Study of Consciousness وتصدر هذه الجمعية ثلاث مجلات متخصصة مكرسة بشكل رئيسي للار اسات العلمية و الفلسفية هي : : الوعي والإدراك"، "الوعي و العاطفة"، "الوعي وعلم النفس" وتنظم ايضا مؤتمر ا نصف سنوي، 
لماذا؟ لان العديد من فلاسفة اللغة رأوا ان الكثير من الاسئلة التي كانت تثار في فلسفة اللغة هي حالات خاصة تتعلق بطبيعة العقل ،وان استعمال اللغة ليس سوى تعبير اولي لقدراتتا العقلية الاساسية ،ولن نفهم بصورة كاملة كيف تقوم اللغة بوظائفها ان لم نفهم اولا نمط حضور ها و اثتغالها في العقل .لذا اصاب البحث في فلسفة اللغة نوع من الركود . فضلا عن ذلك فان الفلاسفة المحترفين المهتمين اكثر بنظرية المعرفة Epistemologyالذات والموضوع هي قضية الفلسفة الاساسية، او القضية المركزية ،و انتقلوا للبحث في مسائل بناءة عوضا عما كانوا يقومون به من البحث في مسائل المعرفة التقليدية. وان افضل وضع لهذه التفلسف البناء هو التعمق بدراسة العقل الإنساني. التي تفضي بالتأكيد للسؤال عن وجود الانسان ذاته، كذات وراعية انسان حر، ومسؤول، وعاقل، وناطق، واجتماعي ،وسياسي ،وفنان ،ومبدع يعيش في عالم مكون بكليته من

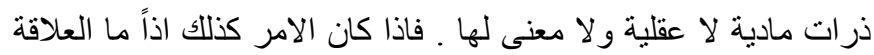
بين الوجود الإنساني وبقية انحاء الوجود.؟ للإجابة عن هذه الاسئلة يتوجب البدء بدراسة العقل، لان الظواهر العقلية تشكل جسرا يربطنا مع بقية العالم ،لذا برز للوجود حقل معرفي جديد هو (علم الادر الك المعرفي) و هدف هذا العلم هو الغوص بعمق في طبيعة العقل اكثر مما كان معتادا في علم النفس التجريبي التقليدي ."سيرل "(16-144ص،2007. لكن هذا لا يعني بالطبع انه حقل فلسفي جديد تماما ـ نعم على المستوى الفلسفي لم تكن القضية تطرح بصورة جذرية ، فتم قبول وجود الانسان الو اعي العاقل بصورة تكاد تكون تلقائية ،جر اء هيمنة التصورات الدينية. و مع ذلك فالاستثناءات كانت موجودة، لكن لم تكن لها السيادة للمشهر الفكري في اي من عصور الفلسفة المتوالية ،ويرجح الباحثون صدور كتاب" C.D.Broad " (العقل ومكانته في الطبيعة) سنة 1925 بعده العمل الاكثر تركيز المشكلة الوعي، بالنسبة لبرود ان ظاهرة العقل هي في المحصلة الاخيرة ظاهرة الوعي " Chalmers. Consciousness "and its place in Nature,1998.p.1" صدور كتاب "جلبرت رايل " سنة (1949) باعتباره البداية المؤسسة لفلسفة العقل كفرع جديد في الفلسفة ، فقد شاد به سيرل و عده مرجعا لا غنى عنه للمهتمين بمشكلة الوعي .Searle, John. p. xiv. تأريخيا كانت مشكلة الوعي تتوارى خلف مشاكل فلسفية اخرى، مثل مشكلة المعرفة ،وبصورة اكثر وضوحا ،مشكلة العلاقة بين العقل
في التعريف الاخير، يصبح الوعي الذاتي انطولوجيا. والذاتية في هذه الحالة ليست مسالة تخص الأبستمولوجيا، بل هي مسالة تتعلق بمنزلته الانطولوجية، والذاتي انطولوجياً، غير قابل للرد الى الموضوعي انطولوجياً ،فلا يمكن الاعلان بثقة عن حالة تطابق بين محتويات الوعي وموضو عات العالم الخارجي . الوعي هو ان تمنلاك القدرة على وصف الحالة العقلية التي تعيشها من وجهة نظرك الذاتية ،هو ان تمنلك القدرة على الاجابة على السؤال: كيف يبدو؟ او: مثل ماذا؟.اي شيء من الاشياء حين تجابه بالسؤال عنه . وقد رأى عدد من فلاسفة الوعي انه من المفيد إدخال اصطلاح تقني للإشارة الى الصفة الخاصة التي يتميز بها الوعي ، فالشعور عند الانسان يختلف بحسب المواقف التي يمر بها ، فالثعور اثناء تناول وجبة طعام لذيذة يختلف عن الشعور بسماع اغنية جميلة او تذكر حادثة اليمة و المصطلح المتداول الآن للإشارة لهذه الحالات هو : (كواليا- Qualia). اي الصفات الجوهرية وهذه صيغة جمع اما مفردها فهو (Quale) و المصطلح مأخوذ من (Qualitative) بمعنى الكيفيات ،فكل شعور نختبره يتميز بصيغة كيفية معينة ،وهو فضلا عن ذلك ذاتي ،وبالتالي فكل تجربة واعية تمتاز بالذاتية." Chalmers, the conscious .(Mind,1995,p.IX) ولا اريد الاسترسال في مزيد من التعريفات لأنها تكرر ذات الأوصاف للوعي بطرق مختلفة، وإن أردنا التعبير بكلمة واحدة عن الوعي لقلت انها مفردة "الأنا " فالأنا الواعية التي هي انت وشعورك بوحدة واستمرارية هذه الانا ،منذ ولادتك الى مماتك هذه الانا الواحدة في الزمان هي التي نتكل جوهر الوعي ـ التي تجعلنا نشعر بان هناك عالمين ، و هما عالم الانا و الوعي من جهة ،و العالم الفزيائي الذي يحيط

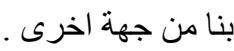
ولنرى الآن كيف عاد الاهتمام للبحث في هذا الموضوع فلسفيا وعلميا من جديد ؟ هناك جملة من الاسباب جعلت من مشكلة الوعي هي المتسيدة للششه الفكري في أواخر القرن العشرين وبداية الألفية الجديدة يجملها "جون سيرل" أحد أبرز فلاسفة الوعي المعاصرين بالتالي: كانت فلسفة اللغة هي المنصدرة للمشهد الفلسفي والفكري الى سنوات متأخرة من القرن العشرين ،وكثير من الفلاسفة راوا ان مجالات فلسفية متعددة هي نتاج الاشتغال في فلسفة اللغة بل وتعتمد عليها في حل مشكلاتها. لكن بعد ذلك انتقل مركز الانتباه الى فلسفة العقل او الوعي 
فذكر بعضها يعطي الانطباع وكأنها هي الوحيدة التي ينطبق عليها الوصف والامر خلاف ذللك تماما. على اية حال ان مشكلة الوعي كانت تتوارى خلف هذه التقيم الكبير للفلسفة ،مثلما تورات خلف مشاكل فر عية اخرى في الفلسفة مثل مشكلة المعرفة. ومن نافلة القول ان الاديان سواء كانت الوضعية منها ام السماوية ـ لا لانهاء امبل لهذا التصنيف لا نها تشترك ببنية واحدة - اسبق من الفلسفة بطبيعة الحال، فان الايمان بالثنائية ملازم لها فالثنائية جزء اساسي من بنيتها الداخلية، وطبيعة المفاهيم التي تستعملها والتي تؤطر هذه البنية (خالق ومخلوق - روح وجسد - عالم فاني و عالم ابدي -الخ ) وربما كانت الفلسفة في نزعتها الثنائية امتداد لهذه النظرة الدينية الثنائية و التي هي الاخرى انعكاس لاستشعار الانسان بوجود عالمين مختلفين فيه اي الاحساس بثنائيته كما اشرت الى ذلك قبل قليل. وحضور الثنائية في تاريخ الفلسفة كان هو الأقوى خلاف الواحدية ،لأنها بيساطةـ اي الثنائية ـ تعبر عن وجهة نظر الأنسان العادي او ما يدركه كل الناس في داخلهم بشكل بديهي من وجود عالمين .و الفلسفة الغربية وخصوصا بعد ان اصبحت اوروبا مسيحية كانت في معظم حالاتها انعكاس للثنائية الدينية المسيحية وتماشيا معها "هنتر ميد. 1975،ص138 ". وهو ما حصل ايضا مع الفلسفة الاسلامية بصورة مدهثة ، لان الفلاسفة المسلمين وقفوا ضد اراء القدماء من الفلاسفة اليونانيين (الواحديين) اللذين قالو البالمبدأ الواحد اصل للوجود او اللذين قالو ان العالم قديم اي لا بداية زمانية له .دفاعا منهم عن الثنائية الاسلامية و عقلنة لهذه الثنائية في ذات الوقت. الارث الايكارتي إن ظهور الثنائية بصورتها الفلسفية الحادة مع ديكارت في العصر الحديث، هي صياغة نموذجية لما يسمى بنظرية التأثير المتبادل ونتويج فلسفي لها. فهي تفترض ان الانسان مكون (Interactionism)

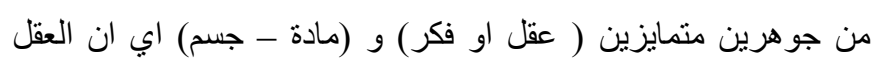
اللامادي يؤثر في الجسم المادي فانت تز غب في تحرك يدك مثلا و الرغبة هي شيء غير مادي لكنها تتحول الى حركة في الجسم من خلال حركة اليد الفعلية وبشكل فوري، وبالعكس اي ان استشعار الجسم الما ما ما ماديز نتيجة ضربة او وخزة فأنها نترجم فورا الى شعور بالألم في الوعي

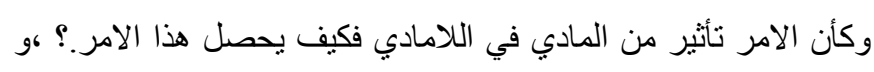
هناك مبدأ فلسفي راسخ هو ان الجوهر قائم بذاته غير محتاج الى شيء خارج ذاته. والجواهر المختلفة ما هويا لا يمكن ان يلتقيا او ان يؤثر هون
و الجسم. لكن طو ال تاريخ الفلسفة ،كان الفلاسفة الذين انشغلوا بمشكلة المعرفة دون بقية مشاكل الفلسفة ،لم تكن معالجتهم للوعي كمشكلة اساسية مستقلة وقائمة بذاتها من حيث ،طبيعته وماهيته ،فلم يكن سؤال مونهال الوعي هو المبتدأ ومنه منطلق بحثهم، بل كان يتوارى خلف اسئلة المعرفة، ادواتها ،وطبيعتها، وحدودها ،ويكون الوعي هو الحصيلة النهائية لعملية المعرفة فإنسان عارف هو انسان يمتلك وعيا ،دون ان وهان إنهان يكون هنالك تساؤل على غرار لماذا الوعي اصلا ؟ لماذا هنالك انسان واعي؟ وما هو الوعي بالنهاية؟ قلت ان المشكلة الابرز التي ترافق معها مبحث الوعي في تاريخ الفلسفة هو مشكلة العلاقة بين العقل والجسم ـ التي ظهرت بصورة جلية في العصر الحديث مع الفلسفة الديكارتية لكن في سياق أوسع ألا وهو نظريته الثنائية الحادة في وجود جوهرين جوهر عقلي ماهيته الأساسية الوعي او او الوني الفكر وجوهر مادي ماهية الاساسية الامتداد. وخير من يجسد هذين الجوهرين في الوجود هو الانسان، لان الجوهرين ، الجوهر العقلي والجوهر المادي بلتقيان فيه . الثنائية تعكس مشكلة الوعي بطرق مختلفة : ان ثنائية المادي واللامادي هي بصورة ما انعكاس لثنائية العقلي و الجسمي وليس العكس ،ان الانسان يستشعر في نفسه اولا هذه الثنائية بشكل واضح ومن ثم بيقطها على العالم الخارجي ـ لكن هناك الكثير من الفلاسفة الميتافيزيقيين يعكسون القضية، فيبيئون من العالم الخارجي ويميزون فيه بين مادي ولا مادي ومن ثم ينتقلون الى الانسان. وربما

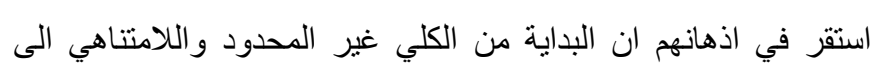
الجزئي المحدود والمتتاهي سبسهل عليهم تفسير الاخير بشكل تلقائي. فضلا عن ان الامر يبدو منطقيا اي الانتقال من الكلي الى الجزئي ،لكن

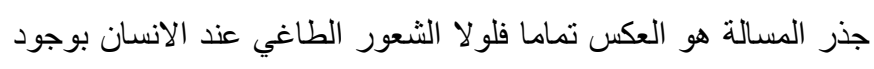
عالمين منمايزين فيه عالمه العقلي اللامادي من جهة وجسده المادي من جهة اخرى، لو لا هذا، لما تجشم الميتافيزيقيون عناء تفسير الوجود الكلي في عالئ بالركون الى الثنائية . وعلى هذا الاساس يمكن تصنيف تاريخ الفلسفة والفلاسفة الى تيارين كبيرين(ثنائيين) و (واحديين) اي بمن يقول بعنصرين منمايزين او

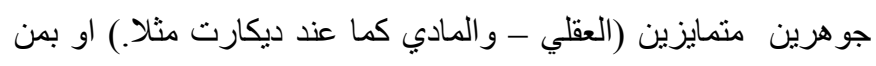
يقول بجوهر واحد(اما عقلي او مادي) مثل الفلاسفة اليونانيين القدماء الذين عاشوا قبل سقراط اوهوبز و سبينوزا في الفلسفة الحديثة . والحقيقية انا اذكر الامثلة على مضض لان كل تاريخ الفلسفة حافل بها 
ويوجد لكل نوع من هذين الجوهرين فرع مميز وملائم لدراسته. فالمادة يدرسها علم الفيزياء، والعقل يدرسه علم اللاهوت الكنسي والفلسفة "ت.ز. لافين - 2014،ص144-145".ان حرية ار ادتي لن تؤثر على لأل سلوك جسدي المادي لانه خاضع للقو انين الفزيائية مثله مثل بقية الاجسام الاخرى ـ العقل غير قابل للتجزئة بينما المادة تقبل ذلك .والاكثر اهمية لإنية من ذلك ان ديكارت اكد ان الانسان قادر على ان يتخيل نفسه موجودا بدون جسم. لا تكمن المشكلة بالنسبة لديكارت في السؤال العام كيف يمكن

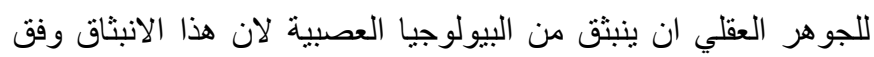

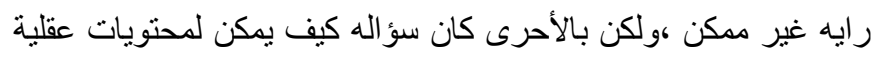

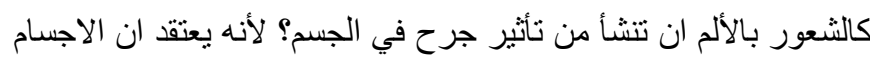
و الادمغة تفتقر الى الوعي ،خلاف الاعتقاد السائد الان حتى بين الثنائيين

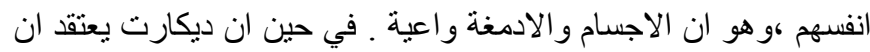
العقل منتشر في الجسم كله وليس هناك عضو محدد في الجسم يكون مسؤو لا عن التعقل ،فالعقل في الانسان ليس كالقبطان في السفينة يحتل هلئل

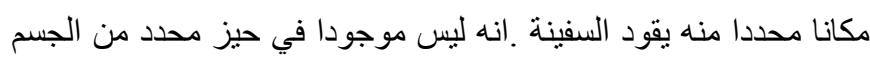

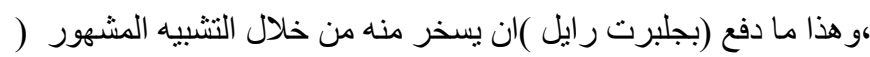

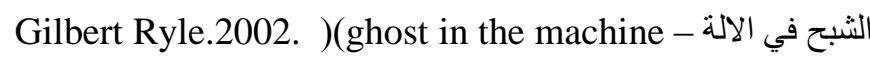

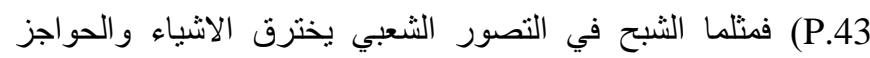

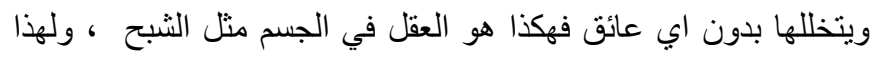
السبب قال ديكارت بإمكانية ان يتخيل الانسان نفسه بدون جسم. لكن

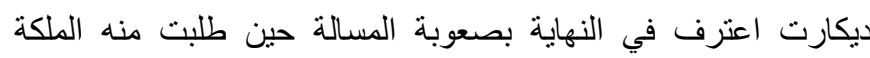
كرستين ملكة السويد ان يفصل لها المسألة بشكل حاسم." يوسف كرم . ص84 " هذا اذا غضينا النظر عن حله الساذج بافتراضه الغدة

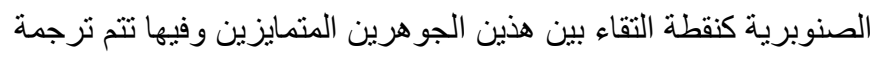

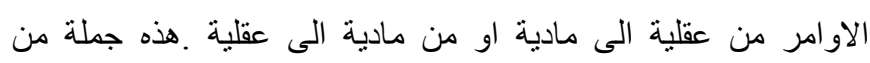

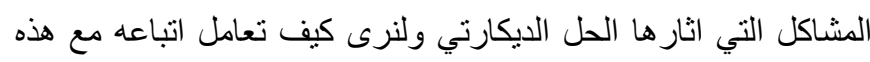

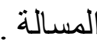

ان اتباعه فيما بعد تجاوزا هذه المشكلة الى حل اكثر غرابة وهو قولهم باستحالة الاتصال بين الجوهرين فهما عالميين منوازيين خلقهم الله

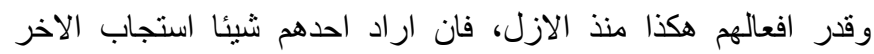
وبصورة منوازية وفورية له لكن دون ان يكون بينهم اتصال. وتسمى

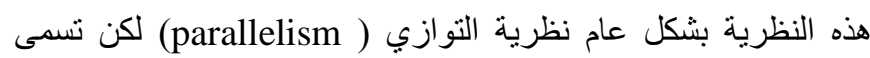
بذهب المناسبة (occasionally causes) حين تم طرحها من قبل "جولنكس" و "مالبر انش" ،وفيما بعد" ليبنتز".
احدهما بالأخر ؟ فكيف يحصل ان يوثر العقلي في الجسمي ، او الجسمي في العقلي. لذا كانت تسميتها بنظرية التأثثر المتبادل تسمية مناسبة جدا

وبما ان هذا التفسير ينطوي على صعوبات كثيرة نواجه الفيلسوف الذي

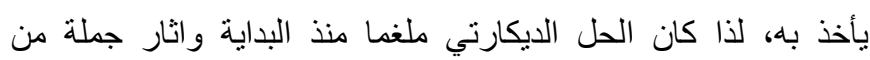

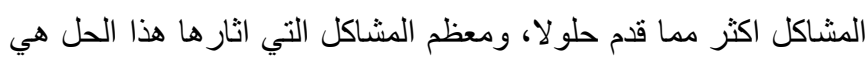

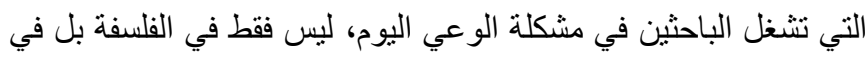
حقول علمية متعددة وسناتي على هذه المسالة لاحقا .

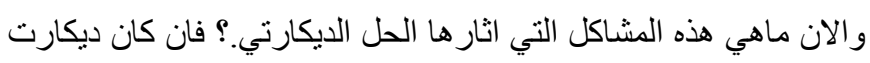

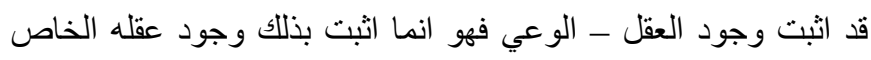
المفرد، لكن كيف يكون الامر مع العقول الاخرى؟ بمعنى كيف يمكن

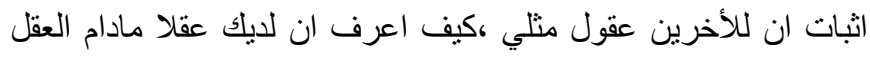
الوحيد الذي اعرفه بصورة مباثرة هو عقلي؟ حسنا يمكن تجاوز هذه

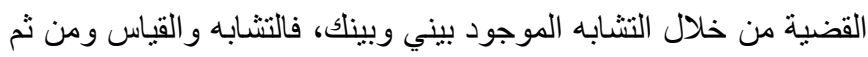

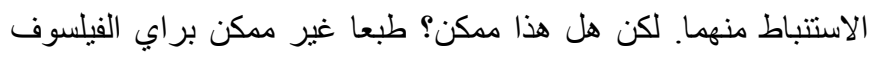

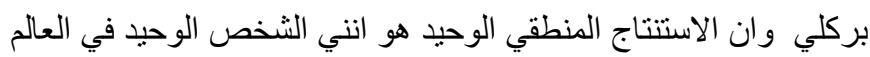
الذي يمنلك حالات عقلية لهذا سمي مذهبه (بالانا واحدية - solipsism).

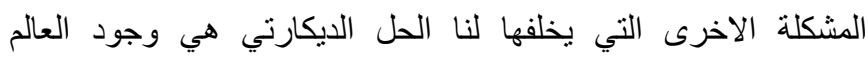

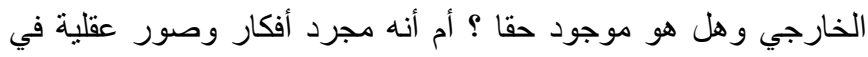

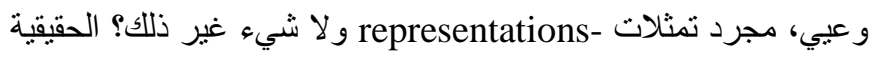
ان ديكارت استنجد بالعون الالهي كي يضمن وجود العالم الخارجي .

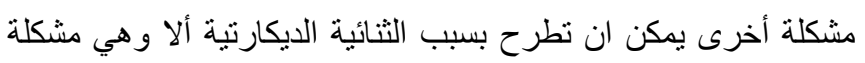

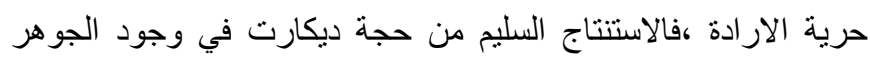

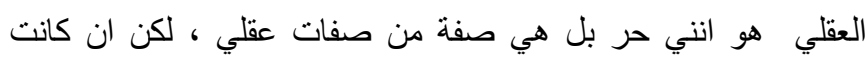

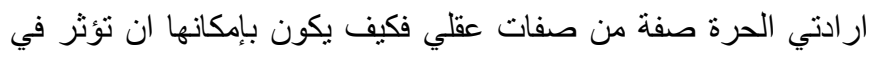

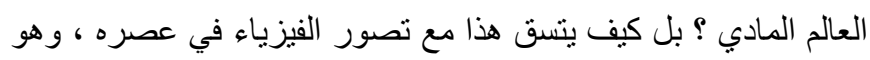

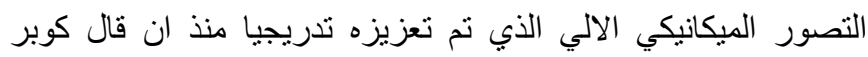

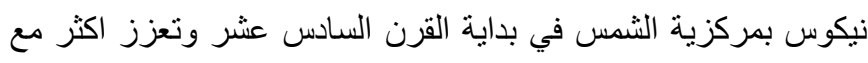

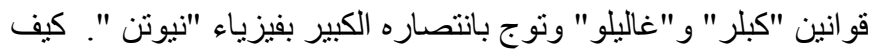

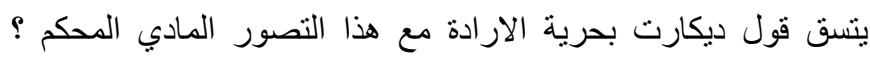

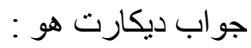
ان العقل لا يشغل اي حيز وليس في حالة حركة وليس جز أ من اية الية مادية، و غير قابل للانقسام .على عكس الجوهر المادي الممتد في المكان الخاضع للحركة الميكانيكية وليس له ارادة حرة او اية صفات لكات اخلاقية. 
هو الانسجام الذي يتحقق بفضل فن الهي ازلي كون منذ البدء هذين الجوهرين المادي و الروحي بشكل فائق الكمال ونظمهما بغاية من الدقة فلو ان واحدا من هذين الجوهرين اتبع قو انينه الخاصة التي هي جزء من كيانه ووجوده ، لاتفق اتفاقا تاما مع الجوهر الاخر ،ويتم كل شيء كما لو كان هنالك تأثير منبادل او كما لو كان الله بضع يده عليهما باستمرار (لبينتز ،1982 ص132-135) فالنفس على سبيل المثال ان ارادت تحريك اليد فان اليد تتحرك على الفور لكن دون ان يكون هناك اتصال مباشر بينهم وانما هو تناسق ازلي بين ارادة النفس في تحريك اليد و استجابة الجسم له .

كانت الثنائية الديكارتية مهمة في القرن السابع عشر لأنها فصلت مجال الدين عن مجال العلم. الا ان ذلك لم يكن بشكل حاسم ان ما حاول ديكارت ان يفعله هو اعطاء العالم المادي الى العلماء وعلم العقل والنفس الى رجال الدين وهي خارج نطاق البحث العلمي المادي لكن هذه كانت تهدئة مؤقتة .لأنه مع الفيزياء النيوتنية ترسخ علم الفيزياء ومعه ترسخ التصور الميكانيكي المادي للكون بصورة حاسمة في المنظومة المعرفية الحديثة ،التي بدأت بالتشكل في اوربا منذ عصر النهضة . لكن يقين الفيزياء النيوتوني اثار شكوك جديدة وجدية ، فتصور العالم بوصفه نظاما ميكانيكيا قد اثارت مشكلات لم يكن بمقدور الفيلسوف الميتافزيقي ان يتملص منها كما حاول ديكارت ان يفعل . و على وجه التحديد ان كون الانسان موجود داخل العالم هو امر يثير تساؤلا عما اذا كان واقعا داخل هذا الاطار الميكانيكي ام لا ؟هل يعني هذا ان الانسان ايضا يخضع لقو انين الفيزياء مثله مثل بقية الاشياء المادية من حوله ام انه استثناء؟ ؛ و انه يشكل مملكة داخل مملكة . واذا كان الامر كذلك فمن اين يأتي هذا الا حساس. والسؤال الان هل نحن استثناء ام لا؟ وماهو العنصر الاستثنائي الذي يجعلنا مميزين؟ بكل تأكيد انتم تعرفون الجواب لأنه مدرك بصورة تلقائية من قبل كل انسان، وهو موجود في كل فرد منا، فالإنسان يدرك انه متميز عن من مله الطاولة او الكرسي من حوله ويدرك انه متميز عن الاشجار وعن الحيوانات ،ذللك لأنه يمتلك عقلا انه يمتلك الوعي . لكن هذه البساطة في ادراك وجود الوعي في كل واحد منا تثير اكثر المسائل تعقيدا وصعوبة على الاطلاق، سواء على المستوى العلمي او المستوى الفلسفي ـ وبما انه لا يمكن تجنب تاريخ الفلسفة ان اردنا معالجة مشكلة فلسفية، لكني سأتجنبه هنا ذلك ان الحل الديكارتي بقي حلا نموذجيا و استغرق جميع الاسئلة بطريقة او اخرى. لان الثنائية هي
يرى جولنكس وتبعه في ذلك مالبر انش انه في كل نشاط حقيقي لابد ان يعرف الفاعل انه يفعل ،وكيف يفعل، وبالتالي فنه يترتب على ذلك بوضوح ان الثيء المادي لا يمكن ان يكون فاعلا عليا حقيقيا ينتج معلو لات سواء في شيء مادي اخر او في جوهر روحي ،لأنه مادام ان الثيء المادي يعوزه الوعي فانه عاجز ان يعرف انه يفعل وكيف يفعل ،وبالمثل ايضا يترتب على هذه المقدمة ان (الانا) من حيث انها روحية لا تنتج بالفعل سواء أكانت في جسمي أم في أي جسم اخر تلك المعلو لات التي تؤدي الى طريقتي الطبيعية في التفكير .فانا الاحظ التغيرات والحركات في بدني لكني لست الفاعل ،الحقيقي لها رغم افعال ارانتي الداخلية، لأني لا اعرف طبيعة الارتباط بين افعال ارادتي والحركات المترتبة عليها في جسمي. حسنا اذا كان الامر كذللك فكيف نفسر الواقعة التي تقول ان الارادات تتبعها حركات في الجسم ،وان التغيرات في الجسم تتبعها احساسات وادراكات في الوعي؟ الجواب هو: ان فعل ار ادتي هو مناسبة (occasionally ) يحدث فيها الله تغير ا او حركة في الجسم و على نحو ممانل فالحدث الفزيائي في بدني هو مناسبة يحدث فيها الله حدثا فزبائيا يقابله في و عيب. ان العقل و الجسم اشبه بساعتين محكمتي الصنع ودقيقتين بالتوقيت لاتؤثر احداهما في الاخرى ولكنهما يثنيران دوما الى ذات الوقت، لان الله جعلهما يتفقان زمنيا في حركاتهما باستمر ار. (كوبلستون. 2013.م4. ص247-248). ان مشكلة الوعي و اسئلته مطروحة هنا بكل حدة ووضوح ،لكن الركون للحل اللاهوتي افرغ الاسئلة من محتواها، وسد الطريق امام التعقق بصورة جدية في البحث عن اجابة .لان استدعاء الله للخروج من المأزق لا تتوافق مع العقل لانه يقضي بعدم جواز هذا التدخل الالهي الا كما يتدخل في سائر الامور الطبيعية الاخرى. وسيتابع (ليينتز ) نفس الحل بل ويستخدم نفس التشبيه في نظريته. يقول: عندما شرعت في تأمل اتحاد النفس بالجسم شعرت كما لو كان قد القي بي في مجهول في عرض البحر ،ذلك اني لم اجد وسيلة ما افسر بها كيف يتسنى للبدن ان يؤثر في النفس وبالعكس .كان ليينتز يعتقد ان هذه العلاقة هي صورة مصغرة لعلاقة الله بالعالم فاذا امكن التوصل الى حل نهائي للأولى امكن تفسير الثانية بالاستناد اليها .وحتى يقلم ليبنتز حله لهذه المشكلة قدم نظريته pre- establish المعروفة في تاريخ الفلسفة باسم (التناسق الازلي (harmony كان يحب دائما ان يورد اسمه مقترنا بها، لأنها بر ايه تفسر تفسير ا نهائيا عملية الادر اك وطبيعة الوعي و علاقة النفس بالجسم ـ ان التناسق الازلي 


\section{هل يمكن لنا ان نعالج مشكلة الوعي دون ان نضع الله في الحسبان؟} مثلما قلت في بداية هذا البحث ان هذا الحقل الدراسي الجديد سريع التطور وتتداخل فيه تخصصات متعددة تتضمن علم النفس، و الفلسفة، و الفيزياء، وعلم الاجتماع والدين والأنظمة الديناميكية و الرياضيات وعلوم الكمبيونر وعلم الأعصاب والفن والبيولوجيا و علم الإنسان وعلم

طبعا يحلوا للكثير من العلماء المتخصصين في العلوم الدقيقة، ان لا يضعوا الله في الحسبان في تفسير اتهم لظواهر العالم المختلفة،لأنه بر ايهم افتراض سابق، و لا يحل المشكلة. فأن اراد احد ما ان يستعين به، فالمنظومة الدينية التقليدية تقدم له اطار ا فكريا لطرح الاسئلة والاجابة عليها لكن بطريقة اخرى. و الديانات بشكل تقليدي تعتبر من المدافعين عن الثنائية بشكل تقليدي لانها تمثل صميم ما تؤمن به من وجود عالمين عالم روحي وعالم مادي . - مان. ما الذي يمكن ان تقوله الفلسفة اليوم بخصوص الوعي ؟ هذا ان كان يحق لها فعلا ان تقول شيئًا. ذكرت في بداية البحث ان الباحثين في الوعي ا يطلقون تسمية (المشكلة الصعبة Hard- Problem) المصطلح الذي صاغه الفيلسوف الاستر الي جالمرز وهومن الناثطين في بحوث الوعي واصدر عدة مؤلفات حول الموضوع يتساءل فيها عن الوعي ولماذا يوجد ؟وماهي وظيفته تحديدا ؟وكيف يمكن له ان ينشأ عن مجموعة من الخلايا المادية والعمليات

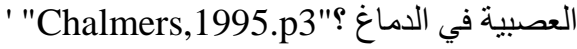

وهي تعد بحق المشكلة الاصعب من بين المشكلات الفلسفية في فلسفة العقل ، ربما صعبة بصورة مستحيلة . انها تفجر السؤال الاولي بكل عنفو انه وهو :كيف يمكن للوعي ان يوجد على اية حال ؟ لماذا نحن كائنات و اعية ؟كيف يمكن للمخ ان يسبب الوعي؟.ان كان له دور في ذللك ياله من سؤال شائك، العقل يحاول ان يدرس نفسه ويعرف ما هو انه مثل

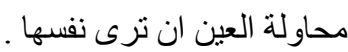
و اذا ما اردنا تصنيفا لمجمل النظريات والآراء المعاصرة حول الوعي فهي بشكل عام لا تخرج عن التصنيف الذي ذكرته سابقا عن تاريخ الفلسفة فهي لا تخرج عن احد الاتجاهيين فهي اما ثنائية او واحدية ولنبدأ بالثنائية المعاصرة، طبعا مع الاخذ في الحسبان ان الثنائية الجوهرانية على الطريقة الديكارتية لم تعد مقبولة اليوم بين الباحثين. ريما هي مقبولة فقط عند اللذين اولوياتهم دينية وليست فلسفية او علمية. والاستثناء هو ما ذكره سيرل وهو دفاع "كارل بوبر وجون اكليس -
عقيدة الانسان العادياو بتعبير اصح هي الموقف الطبيعي للإنسان العادي ،قبل ان تصبح مذهبا فلسفيا. والاسئلة مازالت هي ذاتها. وسأستبعد المثالية لأنها ببساطة نطرح بشكل عام ان الوجود هو في جوهره عقلي وان العالم المادي الذي نعيش فيه هو ليس سوى نوع واحد من الحقيقة العقلية الاساسية ،و هو راي ليس له اية تاثثر حاليا على فلسفة الوعي. ربما الراي الوحيد الجدير بالذكر هنا هو نظرية الظاهرة الثانوية و التي كانت شائعة عند ماديي نهايات القرن (Epiphenomenalism) التاسع عشر وبداية القرن العشرين ـ وهذه النظرية تبدو ثنائية لكن بطريقة مختلفة ومخففة ، فهي برزت نتيجة للصعوبات الكثيرة التي تطرحها نظرية التأثنر المتبادل كما مر بنا ـ تدعي هذه النظرية ان العقل و الجسم صحيح انهما متمايزان عن بعظهما ولكن الجسد يؤثر في العقل لكن العكس ليس صحيح فهو تأثير يسير باتجاه واحد ،اي ان العلاقة بينهما ليست سببية متبادلة مثلما هو الحال في نظرية التأثثر المتبادل فهي بنظر ها علاقة لا تبادلية اي انها علاقة تسير باتجاه واحد فقط ، وهكذا يصبح الذهن مجرد ظاهرة او ظلا للنشاط الجسمي .وكما يعبر برجسون عن ذللك بقوله: ان الوعي يبدو بالنسبة للجسم مجرد هالة نتر اقص فوق

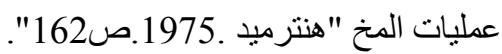
على هذا الاساس فان نظرية الظاهرة الثانوية تقر بوجود الظواهر العقلية لكنها تنكر فاعليتها بشكل كامل ، وبالتالي فان الوعي يصبح مجرد نتاج ثانوي لفاعلية الجسم الفزيائية ، انه ظاهرة مصاحبة لفاعلية الجسم ، وليس له اي دور في تحديد السلوك ، فهي تتكر حرية الار ادة ـ وبالرغم من ان هذه النظرية تبدو متماثنية مع الراي العلمي الذي يرفض القبول باي مفهوم غير مادي وهذه النظرية تكاد ان تفعل ذلك ،الا انها رفضت من قبل الكثيرين، وليم جيمس مثلا الذي يرى انها تجعل من الوعي اثبه بظل ير افق خطوات السائر ولا شيء اكثر من ذلك في حين ان تجاربنا وخبرتنا اليومية تخبرنا خلاف ذلك. وفي عالمنا المعاصر اليوم يا ترى كيف تتم معالجة مشكلة الوعي في حقول المعرفة ذات الصلة بالموضوع؟ تبدأ المعالجة من حقيقة ان الفلسفة لم تعد وحدها في الميدان، ولايمكن لها ان تقول شيئا عن الوعي له مصداقية علمية في الوسط الفكري من دون الاستعانة بالعلوم المهتمة بهذه المشكلة. مثلما لا يمكن لها ان تقول شيئا عن الوجود كما كانت تفعل سابقا، بتجاهل حقائق الفيزياء. 
المادية التي تحيط به فان الثنائية ستستمر ان لم يتقدم احد ويحل المشكلة بشكل جذري ويقدم تفسير ا ينسجم مع معطيات العلوم ذات الصلة. لهذا يبرز من فلاسفة اليوم من يدافع عن الثنائية وسأخذ مثلا لذلك هو ديفيد جالمرز - الذي اصدر اكثر من اربعة كتب عن مشكلة الوعي ،فضلا عن الكثير من المقالات .وهو يسعى في ثنائيته الى نوع من الفيزياء يدخل فيها الوعي كاحد عناصر الطبيعة ،اذ طالما بسعى علماء الفيزياء الى العثور على نظرية تفسر كل شيء ( the theory of Everything ) في الكون ، ومسعاهم هذا يقوم على مبدأ ان القو انين الفزيائية هي الاساس الوحيد لفهم العالم وهو ما بسمى بالاختز ال(Reductive) و الذي يعني همي هـي بصورة عامة ان الحالات العقلية الواعية يمكن اختزالها وردها الى بلى حالات فزيائية سابقة عليها، وهي كفيلة بتفسيرها وهم يعتقدون اننا لا نحتاج سوى قوانين الفيزياء لفهم العالم ككل ،بكل تفاصيله ،فعلم النفس يمكن اختزاله تحت مظلة البيولوجيا وهذه ضمن الكيماء التي بدورها يمكن اختزالها في اطار الفيزياء. ،هذه هي الصورة الاكثر تطرفا من الاختزالية ومع ذلك فانهم لا يستطيعون تجاوز ما يسمى (الفجوة التفسيرية، او الهوة التفسيرية - Explanatory Gap) فقد عجز اصحاب الاختز الية في تجاوز ها لأننا نجد الفيزياء لا تكاد تقول شيئا عن مشكلة الوعي ،و غير قادرة على تجاوز ها ،فلم يجد العلم الى الان التفسير الكافي لكيفية تحول الحالات الدماغية الى حالات عقلية وشعورية تمتاز بذاتية بحتة.(Josseph Levine,1999.p.60) هذا من ناحية، ومن ناحية اخرى فأن السعي ور اء نظرية تفسر كل شيء لن تكون كذلك ان لم تستطيع تفسير الوعي. وجالمرز يرى ان الوعي غير قابل للاختزال الى اي من الوحدات الاساسية المعروفة في الفيزياء مما يدعو الى افتراض ان الوعي نفسه قد يشكل وحدة اساسية من نوع جديد ،ولكنها في الوقت نفسه غير منفصلة عن الطبيعة فطالما هناك وحدة اساسية، كذلك توجد قو انين اساسية وفي حالتنا هذه يجب على القوانين ان تكون قادرة على ربط تجاربنا الواعية بعناصر الفيزياء بدون ان تتعارض هذه القوانين مع العالم الفزيائي. لان الاخير يشكل منظومة مغلقة خاصة به و على هذا الاساس سيشكل جسر ا يحدد كيفية اعتماد التجربة الواعية على التغيرات الفزيائية التي تستند اليها ،وهذا الجسر هو الذي سيجتاز الهوة التفسيرية ،فجالمرز لا يققز على قوانين الفيزياء ،بل يؤمن بان الوعي هو جزء

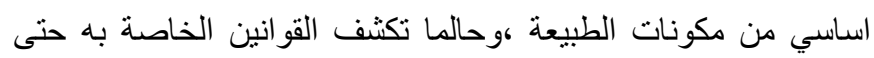
يشكل مع الوحدات الاساسية الاخرى في الطبيعة منظومة شاملة تغير

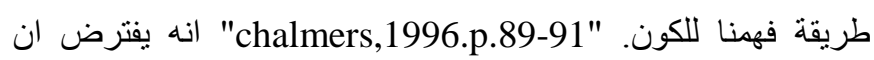

"فohn Eccles مستقل عن الاخر ،العالم الاول هو عالم الاشياء والحالات المادية والعالم الثاني عالم حالات الوعي، كل من هذين العالمين مستقل ومتميز عن الاخر لكنه يتفاعل معه و اقعيا ،ويضيفون الى هذين العالمين عالما ثالث، و هو عالم (الثقافة وكل مظاهرها) وهذه هي نظرية العوالم الثلاث التي يتم تداولها مقرونة باسم بوبر دوما."سيرل، 200.ص 40-41-" اما استحالة الثنائية الجوهرانية على الطريقة الديكارتية فأنها متأتية من استحالة انسجامها مع معطيات الفيزياء المعاصرة التي تقول بثبات (المادة

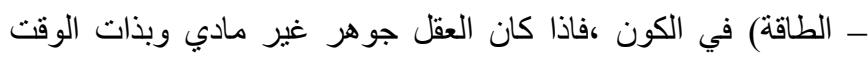
يحرك اشياء مادية فهو يضيف طاقة جديدة للكون، واذا كان الامر كذلك فهذا يعني ان احد اسس وقوانين الفيزياء وهو قانون حفظ الطاقة على خطأ. وهنالك نوع من الثنائية ليس بحدة الثنائية الجوهرانية تسمى (الثنائية الوصفية - property dualism تدعي هذه الثنائية انه مثلما يوجد نوعين من الجواهر في العالم فهنالك ايضا نوعان من الصفات واحدة مادية والاخرى غير مادية والانسان لا يتكون من جوهرين ،ولكن اجسادهم المادية وبالأخص ادمغتهم بالإضافة الى امتلاكها للصفات

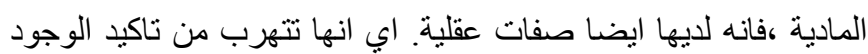
المستقل للجوهر العقلي بشكل تام، لكنها في الحقيقية لا تستطيع تجنب ذات الاعتر اضات التي قيلت بوجه الثنائية الجوهرانية، ومن ابرز هذه الاعتر اضات كيف يمكن لسلسة من الحوادث المادية ان تقود في النهاية الى حدث غير مادي؟ فالثنائية الوصفية لا تستطيع الافلات من هذه النقد عن طريق التلاعب بالتسمية فالإتيان بمصطلح الصفات عوضا عن الجوهر العقلي، لا يسعفها ابدا من الخروج من شرنقة الثنائية التقليدية ومع ذلك وبالرغم من كل هذه الانتقادات للثنائية فأنها ستبقى اثيرة. للإنسان العادي. فضلا عن بعض المفكرين بل وحتى العلماء. فمن المعروف ان النظرية النسبية وفيزياء الكم كانتا قاعدة لفسفات بلفئ وتأملات اشترك فيها العلماء والفلاسفة على حد سواء، لهذا نجد عالم الفيزياء (جيمس جينز) يؤسس للمثالية الرياضية، لان الفيزياء المعاصرة بر ايه تكثف لنا عن وجود كائن اعلا او مهندس عظيم ،وان العالم المادي ظل للحقيقة الخالدة .(ياسين خليل ، 1970.ص183). صحيح انه يشيد نظاما فلسفيا ثنائيا اعتمادا على معطيات الفيزياء، لكنه يعكس بصورة عميقة ثنائية المادي و اللامادي او ثنائية العقلي والمادي. فطالما يشعر الانسان انه يتملك وعيا وهذا الوعي متميز عن الاشياء 
ادعاء بوجود او عدم وجود عقل. لان السلوكية منهج وليست انطولوجيا فلسفية ، لذا فان السؤال عن العقل ووجوده هو سؤال لا صلة له بالموضوعية ـ و وقد تبنى بعض الفلاسفة مقولة السلوكية و وعلى راسهم فيلسوفي الوضعية المنطقية (اوتونيوراث و رودولف كارناب ) وكذلك - (جلبرت رايل ) فاذا كان علماء النفس السلوكيون قالو ا: لا يوجد مكان للثنائية الديكارتية في البحث العلمي، ففلاسفة الوضعية المنطقية يرون ان ديكارت كان مخطئا منطقيا باستدلالاته. وعندهم ان الحياة العقلية

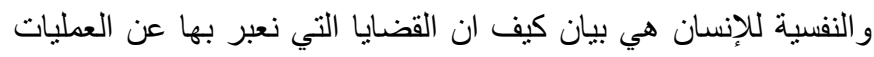

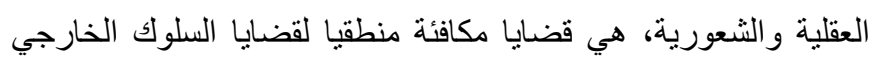

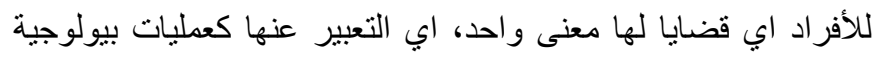

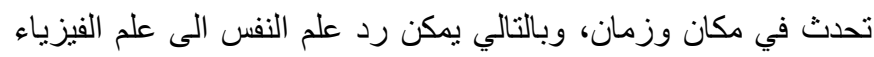

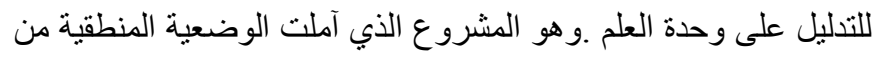
تبنيها السلوكية وتفسير اتها للحياة العقلية ان تحققه ـومع ذلك فلبس هناك من احد منهم قدم شرحا معقو لا وله مقبولية علمية لكيفية ترجمة القضايا العقلية الى سلوكية اذا كانت مكافئة لها منطقيا كما يقولون." ."passmore.John,1972.p.376-378 لكن السلوكية تعرضت الصعوبات في اواسط القرن العشرين ادت الى لى

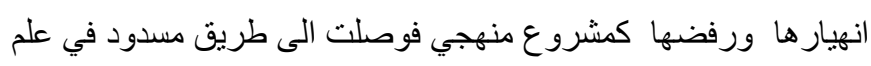

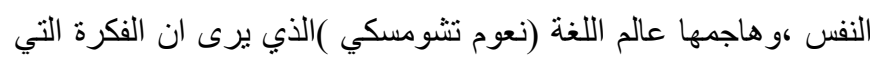
تقول ان البحث في علم النفس هي فكرة غير معقولة كالفكرة التي تقول

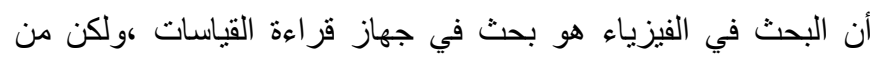

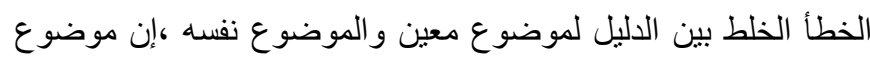
علم النفس هو العقل الإنساني ،والسلوك الإنساني هو دليل لوجود العقل

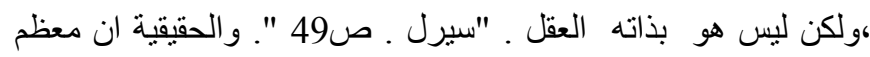
(فلاسفة الوعي ) اذا جاز لي ان اطلق عليهم هذه التسمية يهاجمون

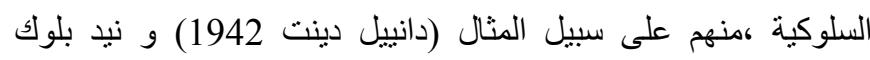
1942) و ايضا (جون سيريل 1932)و (دونالد دافسون 1917) و و( ديفيد

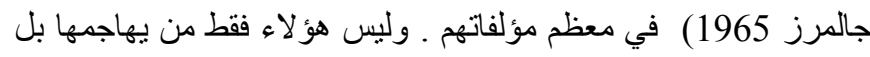

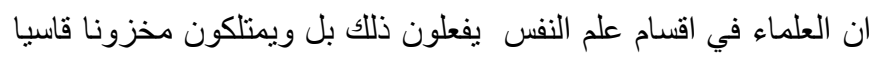

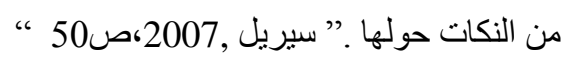

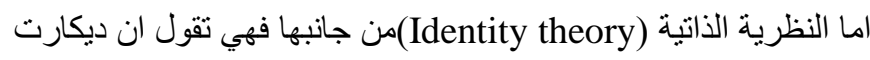

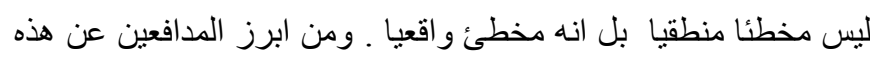

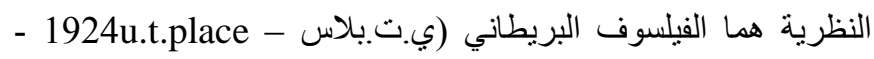

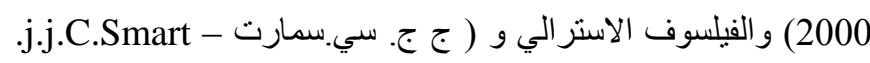

الوعي جزء لا يتجز أ من الطبيعة فهو ليس شيئا مفارقا ،ولكنه لا ينطوي

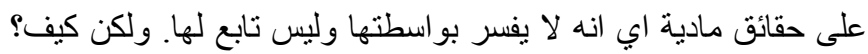
هذا ما لم يجب عليه جالمرز.

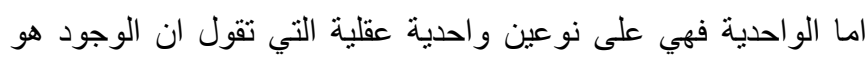
اساسا عقلي او روحي بمعنى اولوية الروحي و العقلي على بقية الاشياء

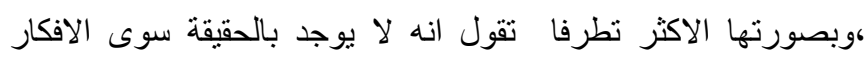

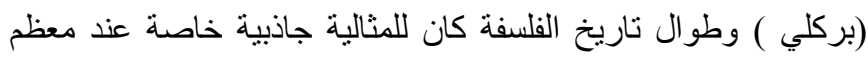
الفلاسفة وبالذات الفلسفة الالمانية، وسأكتفي فقط بهذه الاشارة للمثالية السبب انها ليست مؤثرة في الوقت الحاضر باي صورة من صور التأثير

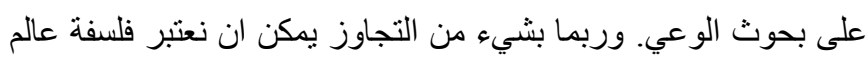

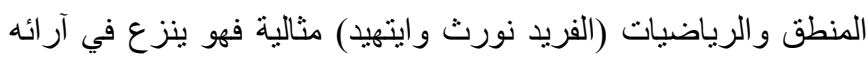

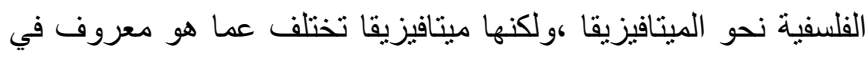

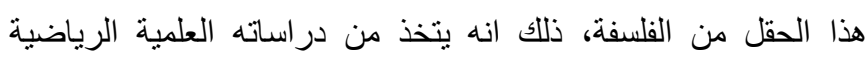
والطبيعية اساسا لهذا الاتجاه. كان وايتهيد من اثد المنتقدين للثنائية

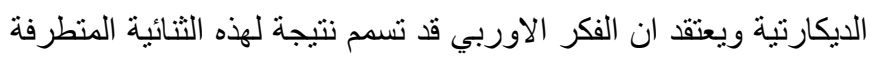
،لذا كانت محاولته منصبة على تأكيد حقيقة واحدة هي كون العقل و المادة

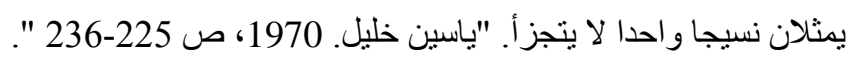
اما الواحدية بثكلها المادي. فهي الاكثر حضوا الانئ الانين في الاوساط الفلسفية

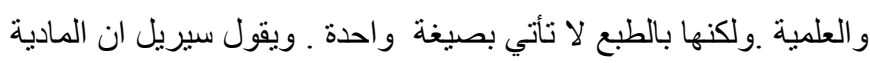

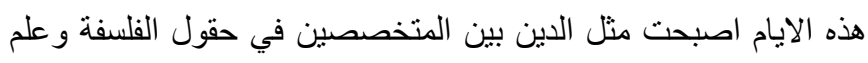

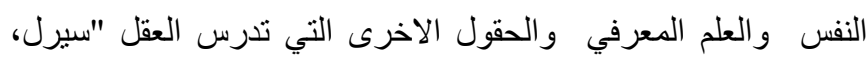
2007،صن46

ان المصطلح المحبب لدى جميع الوان المادية هو (الاختزال -

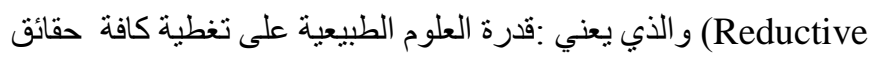

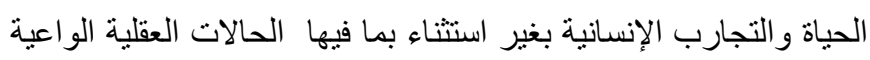

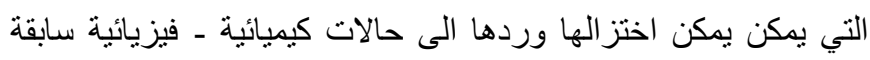

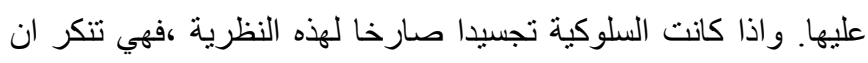

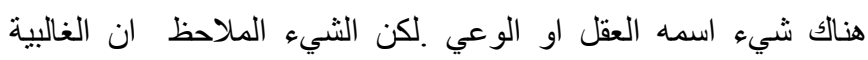

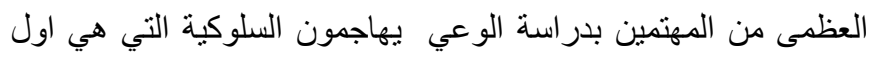

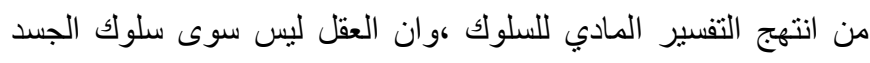

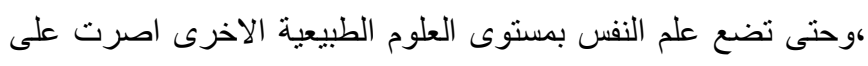

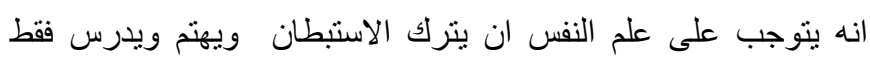
السلوك الذي يمكن ملاحظته بصورة موضو عية وتجريبية، وبهذا يمكن لئن

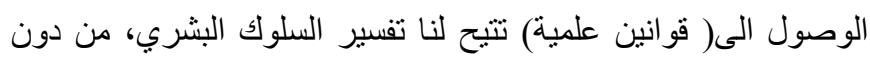


ف فليس هنالك لغز في الامر ولا مشكلة صعبة. وتقول ايضا ان الثيء الذي يجعل الحالات الدماغية حالات عقلية هو نوع معين من الوظيفة في السلوك العام للكائن العضوي ـ و هنالك بعد مهم لتصور الوظيفية للحالات العقلية ،فهي تدمج العالم العقلي بعالم مألوف من الموجودات الوظيفية. فاذا سألنا مثنا : ماهي العجلة ؟ او ما هو الثرموستات؟ او ماهي الساعة ؟ يمكن الاجابة عن جميع هذه الاسئلة سببيا بوصف الوظائف التي تقوم بها العجلات و الثرموستاتات والساعات، فنحن لا نعرف اي من هذه الاشياء بواسطة مكوناتها المادية، فيمكن صنع الساعة من اتراس ودواليب ،ويمكن صنعها من الساعة الرملية، ويمكن صنعها من الكوارتز النابض، اي يمكن صنعها من العديد من المواد المادية ،ولكن الصفة التي تعرف الساعة بوصفها ساعة هي انها الة مادية تمكننا من قياس الوقت .وبالمثل يمكن قول ذات الثيء عن العجلات والثرموستاتات. والحالات العقلية هي منل الساعات والعجلات والثرموستاتات، لا نعرفها عن طريق مكوناتها المادية ولا بواسطة اي جوهر عقلي ديكارتي، ولكن بالأحرى بواسطة علاقاتها السببية. وتعتقد الوظيفية ان كل موجود دون اسنثناء مربوط بعلاقات معينة مع منبهات داخلية ومع حالات عقلية اخرى بإمكانه ان يسبب سلوكا خارجيا. ارادت الوظيفية الاجابة عن السؤال: لماذا ننسب حالات عقلية واعية للبشر؟ وقد ار اد الوظيفيون معرفة طبيعة الحالات الدماغية الباطنية التي تمكنهم من معرفة السلوك سببيا، وكيف تختلف الحالات العقلية عن بقية انواع حالات الدماغُ؟. واحد من هذه الاجوبة هو: ان السؤال ليس فلسفيا او بكلمة ادق غير مناسب للفلسفة على الاطلاق .ويتوجب تركه لعلماء النفس و علماء النيروبيولوجيا ـ ان الدماغ يشبه (الصندوق الاسود) ينتج سلوكا كرد فعل لمنبهات ،و الفلاسفة ليس بحاجة لان يعرفوا مضمون الية عمل هذا الصندوق، بالرغم من انها لا تتناسب مع الفضول العلمي و المعرفي الذي عرف عن الفلسفة (سيرل.2007، ص250-58). و هنالك راي اخر للوظيفية عد حين ظهوره أهم واقوى نظرية في العقل في العقود الاخيرة من القرن العشرين .هي ان العقل كومبيوتر رقمي ،وكآلة من هذا النوع فهو ينفذ عمليات حسابية عن طريق تطبيق برامج ،وما نسميه العقل هو برنامج او مجموعة من البرامج ،ولكي نفهم القوى المعرفية الإنسانية فأن كل ما نحتاج اليه هو اكتشاف البرامج التي تقوم بتنفيذها الكائنات البشرية فعلا عندما يستعملون قو اهم المعرفية .وقد اعتقد الكثيرون ان هذا الراي حل بصورة نهائية المشكلة التي واجهت الفلسفة طوال تاريخها ،وتم انجاز هذا الحل بتعاون عدة علوم : علم النفس
2012-1920) يرى أصحاب هذه النظرية بصورة عامة، ان ما نحسبه عقلا هو في الواقع دماغ وان ما نسميه بحالات الوعي هي حالات دماغية بمعنى هنالك تطابق بين الحالات العقلية والحالات الدماغية. بعبارة. اخرى ان الوعي الذي نحسبه شيئا بالإضافة الى الجسد هو في الحقيقة امتداد للعمليات الفيزيولوجية الجسمية والتي هي بدور ها امتداد للعمليات الفزيائية في العالم الذي نعيش فيه ونخضع لقو انينه. ويرى بلاس انه لا يعني بأن الوعي عملية تحدث داخل المخ، بل يعني انه يمكن رد القضايا عن الاحساسات والصور العقلية او تحليلها الى قضايا عن عمليات داخل المخ. و الى المعنى نفسه ذهب سمارت في قوله ان الاحساسات عمليات في المخ لا بمعنى امكانية ترجمة القضايا عن الاحساسات الى قضايا عن عمليات داخل المخ .ان ما تعنيه هذه النظرية ،هو ان ما تقرره عبارة الاحساس هو ذاته في الواقع عملية داخل المخ .ليست الاحساسات سوى . عمليات داخل المخ ـ وحين نتساءل عن مبررات رفض دعاة الذاتية تبرير الهوية التي تتأسس على التكافؤ المنطقي كما كان يقول الفلاسفة السلوكيون، الجواب: ان ذلك يرجع كما يقول بلاس الى ان قيام الهوية على اسس منطقية يؤدي الى الاعتقاد ان مجرد بيان استقلال معنى اي قضيتين استقلالا منطقيا يكفي للاعتقاد ان الكيانات التي تعبر عنها القضيتان وهما طرفا التكافؤ، ستكون كيانات مستقلة من الناحية الانطولوجية .في حين ان الامر ليس هكذا دائما، ومن الحالات الاستثنائية هي طبيعة العلاقة بين العمليات في المخ و الوعي .لكن تبقى حقيقة ان هذه النظرية هي نظرية منطقية اكثر منها تجريبية وان اكثرت من مصطلحات الفسيولوجيا ـ ومن ابرز من انتقدها هو الفيلسوف الامريكي (دونالد دافدسن 1920-1997 ). "بهاء درويش.2002،ص. 18-17". ويقدم نظرية قريبة جدا من النظرية الذاتية يسميها سيرل ( بالواحدية الثاذة- Anomalous Monism) (سريل .2007،ص.66) و النظرية المادية الاخيرة التي سأذكر ها هنا - لا نه توجد اراء مادية اخرى كثثرة وهي خليط من العلم والتأمل الذاتي والرغبة في صياغة Eliminative - نظرية و غير ها من الأسباب ، مثل (المادية الاقصائية - Materialism النظرية الاخيرة هي ( الوظيفية - Functionalism ) وهي نظرية لها حضور كبير في الوقت الحالي اكثر من اي لون اخر من الوان المادية . الوعي عندها هو جزء لا يتجزأ من العمليات الدماغية المعقدة، لذا لا جدوى من السؤال عن سبب تطور الوعي لان اي كائن تطور بحيث اصبح يمنلك ذكاء و ادر الك حسي وذاكرة ومشاعر يكون و اعيا بالضرورة 
الاكو اب لا تشعر ولن تو اجه مشكلة في القول ان الاو اني و الاكو اب ليست واعية، لكن اذا انتقلت الى كائنات حية مثل الخفافيش، فستجد انك لا يمكنك ان تعرف كيف يكون الحال، لكن لو فكرت ان هناك حالا معينا تكون عليه كما لو كنت خفاشا ،فانت تعنقد ان الخفاش كائن واع. وقد ضرب (ناجيل) بالخفافيش مثلا لأنها مختلفة عنا تماما ، فهي تطبر وتعيش معظم حياتها في الظلام، وتتدلى راسا على عقب من الاشجار ، او في كهوف رطبة، وتستخدم نظام سونار - بدلا من الابصار - لرؤية العالم، و هكذا تعرف طبيعة العالم من حولها .فكيف يكون الحال ان كنت تدرك طبيعة العالم حولك بهذه الطريق؟ لا فائدة من تخيل نفسك خفاثا ،لان الخفاش الناطق المثقف لن يكون خفاشا طبيعيا على الاطلاق، وفي المقابل اذا اصبحت خفاشا طبيعيا، فليس في مقدورك التفكير او الكلام ،فلن تسنطيع الاجابة على سؤاللك .ويمكن للمرء ان يمتلك معرفة كاملة بميكانزيم النيرولوجيا و البيولوجيا الخاصة بالخفاش ومثلها يمتلك معرفة كاملة عن جميع العمليات الحيوية التي تمكن الخفاش من الطيران ،بالر غم من كل هذه المعرفة فيبقى هناك شيء ناقص عن معرفة هذا الكائن . ما معنى الخفاش من وجه نظر الخفاش ؟وما نوع الشعور الذي يميز الخفاش كخفاش ؟ و يرى (نايجل) اننا لن نعرف الاجابة ابدا طالما لانعرف الخاصية الذاتية للوعي، وخلص الى ان المشكلة لا حل لها. " بلاكمور

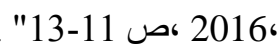

و هناك حجج اخرى اصبحت معروفة الان ضد الوظيفية ،منها حجة (ند بلوك) (الامة الصينية) وحجة (شاؤول كرييك) (المسمى الصلب)، وكذلك حجة (جون سيرل) ( الغرفة الصينية) وحجة امكان وجود (الزومبي )"سيرل.b,2007 صb7 - 80" حيث لا يتسع المجال للتفصيل فيها ،لكنها اضعفت الوظيفية الى حد كبير. هل هناك امل؟: - 20 - مل بعد هذه المسح المختصر لمشكلة الوعي، والنظريات المختلفة التي حاولت ان تقدم تفسير اله، فأن المشكلة بقيت دون حل الى الآن. اقصد حلا نهائيا نستطيع الركون اليه بلا تردد، ان مبدان الدراسة والبحث ماز ال مفتوحاً، وهناك اغر اء مستمر لكثثر من الفلاسفة والعلماء اصحاب التخصصات الدقيقة ذات الصلة، ان يخوضوا غمار البحث في هذا الموضوع ،فعلى سبيل المثال صرح مرة عالم الفيزياء الفائز بجائزة نوبل صاحب نظرية الاوتار الفائقة (د.ميشيو كاكو) بان لديه فضول فوي لدر اسة هذه المشكلة ويستغرب قلة البحوث في الموضوع بالرغم من (*) أهميته.
المعرفي و علم اللغة و علوم الكومبيوتر و الذكاء الاصطناعي ـوبدا للجميع كما لوان حل المشكلة الصعبة قد وجد: ان الدماغ هو كمبيوتر رقمي ،المخ هو كومبيونز والعقل هو برنامج او مجموعة من البرامج ،فالعقل بالنسبة للمخ هو مثل (البرامج - software) بالنسبة (للعتاد الصلب (hardware للكمبيوتر. وبدأ وكانه مع هذا الجواب حصلنا اخيرا على له جواب للمشكلات التي ازعجت ديكارت .وبهذه الطريقة اكتسبت نظرية العقل الكمبيونرية تأثنير ها في بدايات علم المعرفة ـان مشكلة الوظيفية انها تتكر الصفات الخاصة الجوهرية (الكواليا - Qualia) وهو المصطلح الذي تحدثنا عنه في بداية البحث، فالوظيفية تهمل هذه الصفة الخاص و المميزة لوعينا. وكل نظرية بما فيها الوظيفية تتكر هذه الصفة المميزة لو اعينا لهي نظريةز ائفة . كيف ستدرك العالم ان كنت خفاشا ؟ احدى اقدم الحجج ضد الوظيفية هي حجة (الخفاش ) فكيف يكون الحال لو كنت خفاثـا ؟احتل هذا السؤال الظريف أهمية في تاريخ در اسات الوعي ، وقد نال شهرة كبيرة حين عاد فيلسوف العقل الامريكي (توماس ناجيل ) استخدامه في مقال بذات العنوان: سنة 1974 و هي منشورة ايضا ( What it is like to be a Bat ?) ضمن كتابه (mortal Questions. Cambridge.1979) حيث يرى ان كل النظريات المادية والوظيفية التي تحاول ان تفسر الوعي او العقل تغفل حقيقية مركزية وهي: ان ثمة شيئا نشعر به حين يكون المرء في وضع مادي او وظيفي معين. اننا نرى تعارضا بين الخبرة المعاشة القريبة من الذات المفردة، والتصور ات العمومية النظرية التي يبدوكما لو انها تطرح افضل تفسيرات شاملة. فلو افترضنا انتا نمتلك تفسير اكاملا ومرضيا من الناحية الوظيفية والمادية و العصبية لمختلف الحالات العقلية سو اء فيما يتعلق بالمعتقدات و الرغبات و الآمال و المخاوف ..ومع ذللك فأن هذا التحليل سوف لن يفسر الوعي. ولبيان كيف ان مشكلة الوعي تجعل من المشكلة الفلسفية التقليدية، مشكلة العفل - الجسد وطبيعة العلاقة بينهما في غاية التعقيد. (Nagel.Thomas,1979.p.56) ملخص هذه

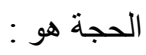
اذا كان هناك حال معين تستطيع به ان ترى نفسك في حال كما لو كنت خفاثـا ،حال يشعر به الخفاش نفسه ،فالخفاش اذا كائن واعي، واذا لم يكن هناك حال معين تكون قادرا على رؤية نفسك فيه ، فالخفاش غير واع. ولو صغنا الحجة بطريقة اخرى تخيل كيف يكون الحال لو كنت كوبا؟ من المرجح ان جوابك سيكون انه لن يكون هناك مثل هذا الحال لان 
ودرجة عالية من الفاي .ونوجد كمية كبيرة من الوعي لدى الفأر فهناك درجة متوسطة لتكامل المعلومات اذاً هناك درجة مهمة من الوعي . ولكن عندما ننزل الى الديدان و الميكروبات و الجسيمات تتدنى كمية الفاي كما تتدنى كمية تكامل المعلومات لكنها لاتز ال فوق الصفر .في نظرية تونوني لا بمكن ان نصل الى درجات صفرية في الوعي فالقانون المقترح هنا هو :كلما ارتفعت درجة "الفاب" زاد الوعي ـ ويقول جالمرز عن هذه النظرية ان لايها ميزة جميلة وهو كونها بسيطة جدا بحيث من الممكن كتابتها على مقدمة التي شيرت او القميص وهو ما يحلم به جالمرز. (**) . . وتذكرني هذه النظرية براي لينتز في الادراكات المتناهية الصغر (petites perceptions)، بالنسية ليينتز الكون مؤلف من ذرات روحية يسميها "مونادات " وهي مر اكز ادر الك بذات الوقت، وتتفاوت درجات الادر اك في هذه المونادات من ادر الك الله الى الادر اكات المتتاهية الصغر التي تتألف منها المادة الفزيائية، فالاخيرة إدراكات" ناعسة "، بمعنى ان الوعي والادر الك يبقى حاضر ا دوما في كل مر اتب الوجود و لا نصل لحالة صفرية مثلما يقول "تونوني " وكلا النظريتين يندرجان فيما يسمى شمول النفس (panpsychism) اي الامتداد بالوعي او النشاط النفس بحيث يغطي جميع انحاء الوجود. لكن يا ترى اين نضع هذه النظرية من تصنيفنا؟ انها واحدية مادية طالما تشدد على امكانية وجود الوعي في اي مكان يجري فيه نمط صحيح من معالجة المعلومات سواء كان هذا المكان هو الدماغ البشري ام جهاز

$$
\text { حاسوب. }
$$

اما التفسيرات الفلسفية للوعي التي تستند على معطيات العلوم الدقيقة مثل علم الأعصاب او علم النفس التجريبي فأنها تميل إلى أن تكون مادية واحدية .فمن الصعب العثور على أتباع للثنائية أو للواحدية العقلية بين العلماء البارزين ربما الاستثناء هو عالم الفسيولوجيا الحائز على جائزة نوبل "جون إيكليس"، الذي دافع عن شكل من أشكال الثنائية التبادلية على غرار ديكارت. لكن ستجد على الجانب الاخر اقصد الجانب الديني الكثيرين ممن يسعون لتجيير نتائج العلوم لصالح الثنائية الحادة على المثال الديكارني، وهو موقف ليس جديد، الجديد هو التوظيف

$$
\text { الايديولوجي لنتائج العلوم. }
$$

قلت في بداية البحث انه لا يمكن للفلسفة ان تدلي براي معتبر دون ان تأخذ أساسيات النظريات العلمية في الحسبان. فعلى سبيل المثال نظرية التطور من اساسيات البيولوجيا، والتطور يشمل جميع الكائنات الحية بما فيها الانسان، و الذي لم يكن انسانا منتصبا عاقلا الا في فتر ات متأخرة من ون
ومع افتر اضي ان القارئ قد اصبح لديه تصور معقول لأبعاد هذه المشكلة ،وكم هي من نوع المشاكل التي تؤرق الذهن وتر هقه ـ فيا ترى هل هنالك أمل ؟ هل نأمل يوما ما ان يكون هناك حل علمي لهذ المشكلة؟.أشك ان الحل سيأتي من عالمنا العربي فهي ليست على قائمة موضو عات الفكر العربي بالمرة، ولا هي من أولوياته ولا تشكل هما له ـ و ولا ضير في ذللك لا نه مهوم بأمور اخرى ـ لكن الثيء الملفت للنظر اثناء كتابتي للبحث هو ان الغالبية العظمى من المهتمين بهذه المشكلة هم من اللذين ينتمون الى العالم الثقافي الأنجلو سكسوني ، فهم في غالبيتهم العظمى أمريكيين و أستر اليين وبريطانيين. ربما نجد هنالك باحثين من دول أوربية أخرى لكن للأمانة لم يصادفني اي اسم خلال البحث، هذه ملاحظة عابرة ليس من ورائها اي قصد عنصري او تشكيك بالدوافع العلمية على الاطلاق .

وبعد ان تبلورت المشكلة بصورتها النهائية في العالم المعاصر ، اما ثنائية او واحدية مادية في معظم الحالات، اصبح بالإمكان تصنيف الباحثين تحت هذين المسميين العريضين، وكل اسم منهم تلازمه الفكرة التي اتى بها ،فعلى سبيل المثال الفيلسوف ديفيد تشالمرز تعد نظريته نوع من الثنائية ، فهو يجادل بأنه بالإضافة إلى المادة، والجاذبية، و المكان، والزمان فإن الوعي هو مكون أساسي ثانٍ في العالم. آما الفيلسوف الامريكي "بول تشرشلاند" فهو واحدي "مادي اقصائي"، لأنه ينكر وجود شيء اسمه الوعي. اما "جون سيرل " فهو واحدي "مادي انبثاقي"، فالوعي عنده هو مستوى متميز من الظو اهر الناشئة من نشاط الدماغ بمستوى أقل ، و الذي لا يوجد إلا عند تجربته. و هكذا مع كثير من المفكرين و العلماء المعتمين بالمشكلة، والشيء اللافت ان جالمرز في اخر محاضر اته عن الوعي التي القاها متلفزة في ملتقى "TED" رشح نظرية باعتبارها النظرية الرائدة الآن، وهي نظرية طرحها عالم الاعصاب "جوليو تونوني " سنة 2008 وهو عالم اعصاب وطبيب نفسي ايطالي مقيم في الولايات المتحدة. تدعى( نظرية المعلومات المتكاملة) اختصـار ا تعرف ب (IIT) ربط هذا العالم الوعي بالمعلومات ،فيثما توجد معالجة للمعلومات يكون هناك و عي ، ومعالجة المعلومات المعقدة تعني وعيا معقدا كما هو موجود عند الانسان ،ومعالجة المعلومات البسيطة تعني وعيا بسيطا. وقام بتطوير هذه النظرية مع نظرية رياضياتية في نسق رياضياتي متكامل، ووضع مقياس يقيس كمية المعلومات يسميه (Phi) - فاي )ويفترض ان "الفاي " ينو افق مع الوعي .لذلك ففي المخ البشري هناك كمية هائلة من المعلومات المتكاملة 
خاص في الكون. فكل شيء يبدو منشابهاً، و لا توجد أماكن خاصة. وتم تضمين هذا الحقبقة بشكلٍ مطلق داخل نماذجنا الحالية عن الكون و المبنية على نظرية النسبية العامة لآينشتاين. اذاً نحن لا نشكل مملكة داخل مملكة، ولا نحظى باي امتياز خاص دون بقية الكائنات. و هذا الاعتر اض له يوجه ضد المدافعين عن جوهر انية الوعي المطلقة و اللذين يتماهون تماما مع الطروحات الدينية التقليدية وان تزيت بزي التحليل الفلسفي و العلمي . ونحن لا نستطيع تجاوز الارتباط الواضح بين عمليات الدماغ وتشكل الوعي ،فهذه من الحقائق الراسخة في كثير من العلوم، فالدماغ البشري لديه اكثر من مئة مليار خليّةٍ عصبيّة تتصل ببعضها بمتاهة من مئة تيريليون وصلة عصبيّة. ووفقا للتقدير الصادر عام 2015 عن معهذ سالك في سان دييغو - كاليفورنيا، فإن هذا يساوي، بمقياس سعة وحدة تخزين المعلومات التي تقاس بالبيتابايت: ملايين من الجيجابايت." ريتشارد ويب -2017". كلها تعمل معا في اقل من جزء من الثانية

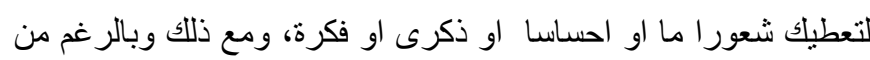
هذا الارتباط الواضح بين عمليات الدماغ و الوعي ، فإن معظمنا بعاني من وهم كبير ا أثناء تقييم قدرتتا على المعرفة الذاتية، وهذا الوهم هو أن ذاتتا موجودة بعيدا عن جسمنا المادّي على طريقةٍ ديكارت الذي كان يعتقد بإمكانية وجود ذاته المحضة بدون جسده ـ لكن علماء الأعصاب اليوم ويتبعهم في ذلك بعض الفلاسفة "سيرل مثنا " أن هذا النوع من بن

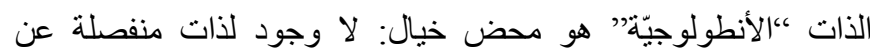
الدماغ الذي يتفاعل معها. إن هذه “'الأنا’’ التي نشعر بها، هي نتيجة

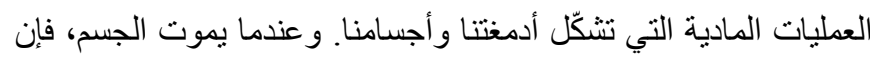
"الأنا" تموت معه ـواذا كان الامر كذلك فقد لا تكون هذه هي النهاية المرجوّة لرحلتنا الفلسفية لمعرفة ما هو الوعي.

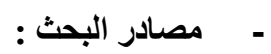

1. ابر اهيم مدكور، المعجم الفلسفي، مجمع اللغة العربية ،الهيئة العامة لشؤون المطابع الاميرية ،القاهرة ، 1983

2. بلاكمور، سوزان، الوعي:مقدة قصيرة جدا، ترجمة ،2016، مصطفى محمد فؤاد ،ط1، 1ؤسسة هنداوي 3. بهاء درويش- فلسفة العقل عند دونالد دافدسن ،منشاة المعارف

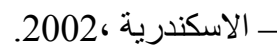

4. هوند تدرش، معجم اكسفورد للفلسفة ،ترجمة نجيب الحصادي ، لبييا ،المكتب الوطني للبحث و التطوير، المجلد الثاني، دون ناريخ.
التطور ؛ لذا نسنطيع ان نستنتج انه كانت هنالك حقب من التطور شهدت غياب تام للوعي بصورته البشرية، اذاً ظهر الوعي هو حدث تاريخي، بمعنى انه حدث في زمان ما من ازمنة التطور وربما في زمن متأخر في التاريخ التطوري ، فلا بمكن للوعي ان يكون جزء اساسي من مكونات العالم حاله حال قو انين الفيزياء، اذ يمكن تصور العالم بدون الوعي ،لكن لا يمكن تصوره بدون قوانين الفيزياء ـهذه حجة ضد فرضية جالمرز الذي يبدو انه يتجاهل هذا المبدأ. وليس هذا دفاع عن المادية من جانبي، فهي لا نشكل اي اغراء لي في قضية تفسير الوعي ،فانا مؤمن تماما بفرادة الوعي ،وهو من الالغاز التي عجزت البشرية الى الان عن ايجاد تفسير مقنع له ،وان وجد هذا التفسير يوما ما ، فسيكون ربما اهم فتح علمي انجزته البشرية في تاريخها ــوقد الف الاستاذ" جون لويس" كتابه "الانسان ذلك الكائن الفريد " والذي يعد دفاعا نموذجيا عن فرادة الانسان بين الكائنات الحية ،وهجوما عنيفا ضد الاختزالية بكل صورها والفرادة التي يتحدث عنها لويس مناتية من امتلاك الانسان للوعي ،ومع هذا فأنه بالرغم من تبجيله لهذه الصفة

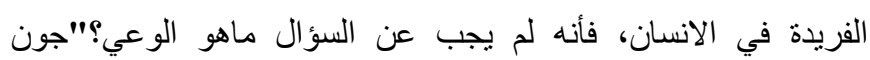

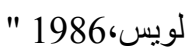
لان هذه الفرادة والتميز للوعي تثير بعض الثكوك ، فاذا كان امتلاكنا للوعي هو شيء فريد ومتميز خاص بنا نحن بنو الانسان دون بقية الكائنات الحية الاخرى ،فهذا يستدعي ايضـا ان يكون المكان الذي نعيش فيه ايضا يمنلك هذه الفر ادة ـ اقصد كوكب الارض-، فاذا كنا مميزين حقا بامتلاكنا الوعي ،فان الامر ليس كذلك بالنسبة لكوكب الارض التي نعيش

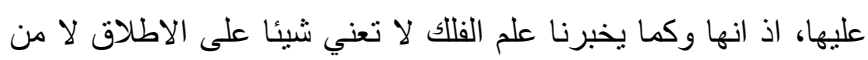
حيث الحجم و لا الموقع ولا اي شيء اخر.

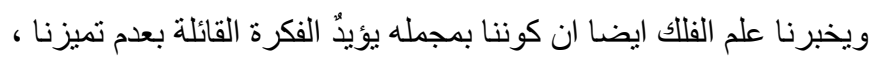
لا نحن، و لا الأرض التي نعيش عليها كذلك. كانت بداية هذه الفكرة تعود عصر النهضة واكتشاف كوبرنيكوس في بداية القرن السادس عشر أن لان الأرض تدور حول الشمس، و اطاحته بنظام بطليموس المبني على اساس ان الارض هي مركز الكون وان الثمس وبقية الكواكب تدور حولها. فحينها وبشكلٍ مفاجئ لم نعد مركز الكون. وضرب غرور الانسان وادعاءاته بالتميز بالصميم، وتلاشت مركزية الانسان، ومنذ ذلك الحين صار من الواضح أن الأرض مجرد كوكب يدور حول نجم آخر وداخل مجرة كالعديد من المجرات الأخرى. وتحوّل اكتشاف كوبرنيكوس ذلك إلى المبدأ الكوبرنيكي الذي ينص أنه بالمتوسط لا يوجد مكان مميز بشكلٍ 
cnn قال العالم ميثيوكاكو هذا الكلام في لقاء اجرته معه محطة الامريكية في برنامج حواري حول مستقبل الذكاء الصناعي ،واللقاء موجود على الشبكة العنكبوتية موقع اليوتيوب

(**) المحاضرة القاها جالمرز في نادي (TED) للمحاضرات العلمية

وهي محاضرات متلفزة وعنوان المحاضرة هو ( How we can (explanation the Consciousness ted.com/talks

Encyclopedia of philosophy.com Stanford:,13"http://Consciousness

Lacey. A.R. Dictionary of philosophy .third .edition -15

.Department of philosophy ,Kings College, University . of London.1996

Chalmers, David, the conscious Mind, Department - 16 of philosophy, university of Califoriia.1995

Chalmers ,David, Consciousness and its place in -17 .nature,MITPress, 1998

Searle, John. The Rediscovery of the Mind. -18 .Cambridge, Massachusetts: MIT Press, 1994 Ryle,Gilert, The Concept of Mind, Routhledge ,New -york,2002.. 19

Josseph,Levine, Conceivability, Identity, and the - 20

Explanatory Gap,in-Towards Science of consciousness,

MIT press,1999

Passmore.John,A Hundred Year of Philosophy, -21 Pelican Book.reprinted,1972 Nagel. Thomas, mortal Questions. Cambridge.1979 -22
5. كوبلستون ، تاريخ الفلسفة، المجلد الرابع، الفلسفة الحديثة من ديكارت الى ليبنتز ،ترجمة وتعليق ،سعيد توفيق ومحمود سيد احمد مر اجعة وتقديم امام عبد الفتاح امام ،المركز القومي للترجمة ،القاهرة، ط 2013 ،

6. لالاند، موسوعة لالاند الفلسفية ،ترجمة خليل احمد خليل ، المجلد الاول ،منشور ات عويدات ،بيروت- باريس ط 2 ، 2001 . 7. "فلسفة لابينتز- مع تعريب المونا دولوجيا ونصوص اخرى ،مكتبة اطلس ،دمشق ،ط2،

8. لويس ،جون ، الانسان ذللك الكائن الفريد ،ترجمة د. صالح

جو اد كاظم ،دار الثؤون الثقافية العامة ،بغداد ـ العر اق ،ط 21986 ـ 9. ريتشارد ويب، الحدّ الأقصى الذي قد تصل إليه معرفة أي شخص، مقال منشور في مجلة العلوم الامريكية "النسخة العربية " عدد سبتمبر الكويت -2017. وبصدد عدد الخلايا العصبية ،فشتان بين الرقم الذي يذكره هذا التقرير والرقم الذي تذكره سوزان بلاكمور في كتابها "الوعي - مقدمة قصيرة جدا "حيث تذكر ان عدد الخلايا العصبية هو مليار خلية عصبية . ص21.

10. سيرل،جون، العقل :مدخل موجز ،ترجمة، ميشيل حنا متياس كلسلة عالم المعرفة ، الكويت 2007. 11. هنترميد - الفلسفة انواعها ومشاكلها ، 1975 ترجمة فؤاد زكريا ،دار نهضة مصر للطباعة ،القاهرة ،ط2 ، 1975. ياسين خليل، مقدمة في الفلسفة المعاصرة ،منشور ات الجامعة .12 الليبية ،كلية الاداب ،بيروت ،ط 1970,1. 13. يوسف كرم ،تاريخ الفلسفة الحديثة ، بيروت ،ط6، 1983 14 ت،اشرف محمد كيلاني ،مراجعة وتقديم سعيد توفيق 'المركز القومي للترجمة ،القاهرة .ط1 ،2012 